\title{
HETEROTOPIC OSSIFICATION IN PEDICLED INTERCOSTAL MUSCLE FLAPS CAUSING CLINICAL PROBLEMS
}

\author{
Rupert Prommegger, MD, and Georg Michael Salzer, MD, Innsbruck, Austria
}

The pedicled intercostal muscle flap is often recommended in thoracic surgery for prevention of bronchopleural fistula after pulmonary resection or reconstruction of the airways, because of its known potential for neovascularization and its general availability in the thoracic cavity. Apart from skeletal muscle, the pedicled intercostal muscle flap contains vessels, nerves, and more or less periosteum of the adjacent ribs including pluripotent mesenchymal cells that can develop to osteoprogenitor cells, so that ossification of the muscle flap may take place. The potential of this flap to develop heterotopic ossification, which is to be distinguished from ectopic calcification, was observed in experimental ${ }^{1}$ and clinical studies, ${ }^{2}$ but a restriction of its use by this peculiarity has never been reported in the literature. This is the first report to demonstrate that unpredictable heterotopic ossification in the pedicled intercostal muscle flap occasionally may cause severe clinical problems.

PATIENT 1. A 35-year-old woman with extensive adenoid cystic carcinoma of the distal trachea and carinal region had carinal resection and right upper lobectomy, followed by reconstruction of the bifurcation. A pedicled intercostal muscle flap was wrapped around the trachea-right bronchial anastomosis to reinforce it. After a 11/2-year uneventful postoperative course, the patient began to have dyspnea and repeated episodes of bronchitis and mucus retentions in the right bronchial system. She also had pain in the right dorsal hemithorax. Stenosis of the entrance into the right intermediate bronchus, caused by an ossification reaching from the neck of the sixth rib to the dorsal side of the trachea-right bronchial anastomosis, was diagnosed (Fig. 1). The ossified parts of the muscle flap were excised. Histologic examination showed lamellar bone with mature bone marrow. The patient recovered to complete health. She has no symptoms and is free of tumor 7 years after the primary operation.

PATIENT 2. A 39-year-old patient had extended adenoid cystic carcinoma of the distal trachea and carinal region. Bifurcational resection and reconstruction of the carinal region were performed. Seven days after the operation a bronchoscopic examination showed mucosal paleness in the right main-stem bronchus, indicating reduced perfu-

From the Department of Thoracic Surgery, University of Innsbruck, Innsbruck, Austria.

Received for publication August 26, 1997; accepted for publication Sept. 3, 1997.

Address for reprints: Georg M. Salzer, MD, Department of Thoracic Surgery, University Hospital of Innsbruck, Anichstra $\beta$ e 35, 6020 Innsbruck, Austria.

J Thorac Cardiovasc Surg 1998;115:466-7.

Copyright (c) 1998 by Mosby, Inc.

$0022-5223 / 98 \$ 5.00+0 \quad \mathbf{1 2 / 5 4 / 8 5 8 2 1}$

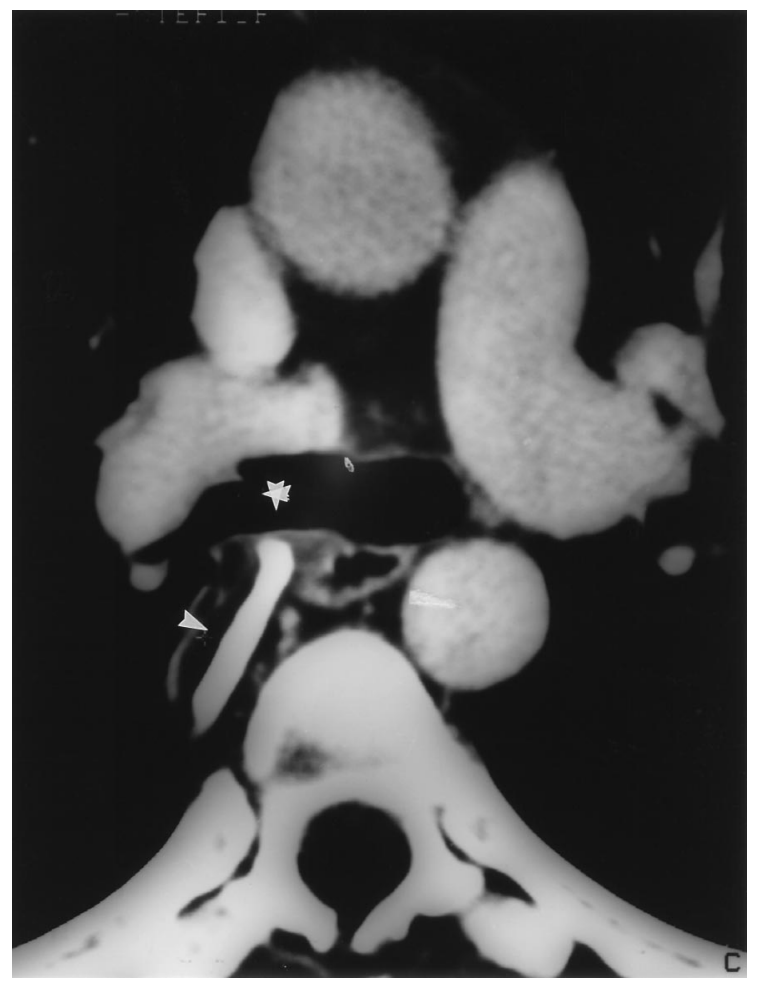

Fig. 1. The arrow shows the ossified pedicled intercostal muscle flap reaching from the neck of the rib to the bronchus intermedius (asterisk) in patient 1 .

sion in the right half of the anastomosis. To provoke neoangiogenesis in the endangered airway section, we prepared two intercostal muscle flaps and wrapped them around the right part of the anastomosis. This method was not successful, and secondary right pneumonectomy was performed. The muscular wrap around the right mainstem bronchus was resected, but the major parts of the pedicled intercostal muscle flap remained at the medial wall of the left main-stem bronchus. Simultaneously, the trachea-left bronchial suture line was covered with newly prepared omentum majus. The patient did well for 6 years until increasing intrathoracic pain and dyspnea occurred. Malacia of the left main-stem bronchus was diagnosed. Repeated stenting was necessary, and 1 year later a bronchoesophageal fistula at the distal end of the endobronchial uncoated wall stent developed. Computed tomographic scanning showed multiple ossifications of the remaining parts of the muscle flap (Fig. 2), reaching to the immediate neighborhood of the fistula. These ossifications fixed the esophagus to the stented left main-stem bron- 


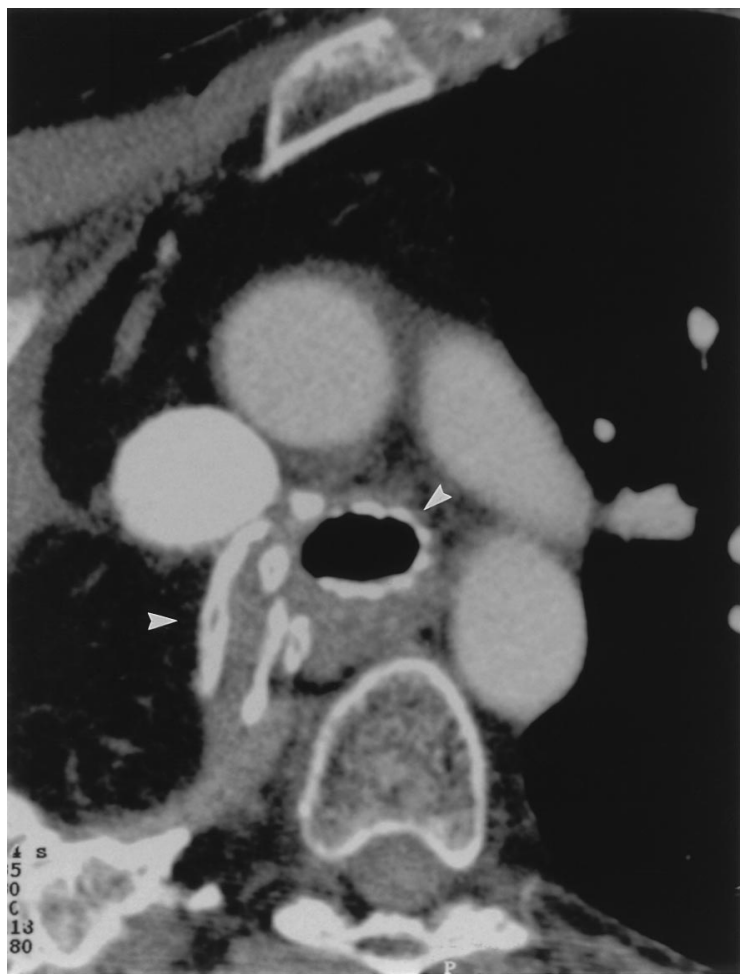

Fig. 2. The multiple ossifications, as well as the wall stent (arrows), are shown. Note the spaces inside the bone, imaging bone marrow in the ossified pedicled intercostal muscle flap in patient 2 .

chus, possibly favoring development of the fistula. At right rethoracotomy, the fistula was divided and the esophageal defect sewn up. Because the bronchial opening was not occluded primarily, and because the omentum had been used 6 years earlier, a pedicled and deepithelialized fasciocutaneous flap from the anterior thoracic wall, which had been precut 2 weeks before the operation, was interposed to occlude the bronchial leak and reinforce the bronchial wall. This method was not successful and the patient died of mediastinitis.

PATIENT 3. A 37-year-old hitherto healthy woman had the acute onset of severe retrosternal pain. A 9 to $6 \mathrm{~cm}$ infracarinal bronchogenic cyst with compression of both main-stem bronchi and compression of the right pulmonary artery, which was nearly occluded, was diagnosed. Because the wall of the cyst was fixed extremely close to the stem of the right pulmonary artery, the cyst could not be excised completely. The epithelium was shaved off from the remaining part of the cyst wall, and a pedicled intercostal muscle flap was sewn to the inner side of the wall remnants to prevent recurrent cyst growth. After 1 symptom-free year she is again having increasingly deep intrathoracic pain, caused by ossification of the muscle flap. Resection of the ossified muscle flap is planned.
The pedicled intercostal muscle flap contains muscle, artery, nerve, and also periosteum of one $\mathrm{e}^{2}$ or two ribs. ${ }^{3,4}$ Ossification of the muscle flap is a well-known

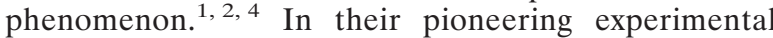
work in dogs, Fell and associates ${ }^{1}$ showed that extensive ossification of the flaps occurred in every case if the periosteum adhering to the flap was not treated with $20 \%$ silver nitrate. The logical consequence to avoid ossification of the muscle flap would be to prepare the flap free of all periosteum, but this will result in reduced stability of the flap by frying of the short muscle fibers, endangering the underlying intercostal vessels. The excellent results of Rendina and associates $^{2}$ in 56 patients prompted us to ask whether the preparation technique of these authors, including the periosteum of only one rib in the muscle flap, is superior to ours, ${ }^{3}$ which always includes the periosteum of two neighboring ribs. Today this question cannot be answered. We had three ossification-related complications in 22 patients who were treated with a pedicled intercostal muscle flap. Also unclear is the value of the clinical use of silver nitrate, ${ }^{1}$ diphosphonates, indomethacin (INN: indometacin), or mild irradiation ${ }^{5}$ for minimizing the occurrence of neoossification of pedicled intercostal muscle flaps in patients. From the clinical point of view, it is hard to relinquish the pedicled intercostal muscle flap, because it is easy and quick to prepare, it allows either a posterior or anterior pedicle to be prepared, and it can reach all the important points in the thoracic cavity.

In the future it will be necessary to gather more data about the frequency, exact localization, and time course of ossification of the muscle flap, which can be gained only by thorough radiologic follow-up of patients. Such a base will open the search for techniques to avoid undesirable changes in a very useful aid in thoracic surgery.

\section{REFERENCES}

1. Fell SC, Mollenkopf FP, Montefusco CM, Mitsudo S, Kamholz S, Goldsmith J, et al. Revascularization of ischemic bronchial anastomoses by an intercostal pedicle flap. J Thorac Cardiovasc Surg 1985;90:172-8.

2. Rendina EA, Venuta F, Ricci P, Fadda GF, Bognono DA, Ricci C, et al. Protection and revascularization of bronchial anastomoses by the intercostal pedicle flap. J Thorac Cardiovasc Surg 1994;107:1251-4.

3. Putz R, Salzer GM. Lunge. In: Kremer K, Lierse W, Platzer W, Schreiber HW, Weller S, editors. Chirurgische Operationslehre. Spezielle Anatomie, Indikationen, Technik, Komplikationen. Erste Auflage. New York: Georg Thieme Verlag; 1991. p. 281-2

4. Papp C, McCraw JB, Arnold PG. Experimental reconstruction of the trachea with autogenous materials. J Thorac Cardiovasc Surg 1985;90:13-20.

5. Myers MA, Minton JP. Heterotopic ossification within the small bowel mesentery. Arch Surg 1989;124:982-3. 